\title{
Aplicação do modelo hidrológico AÇUMOD baseado em SIG para a gestão de recursos hídricos do rio Pirapama, Pernambuco, Brasil \\ (doi:10.4136/ambi-agua.23)
}

\author{
Celso A. G. Santos ${ }^{1}$; Richarde Marques da Silva ${ }^{2}$ \\ ${ }^{1}$ Departamento de Engenharia Civil, Universidade Federal da Paraíba \\ E-mail: celso@ct.ufpb.br \\ ${ }^{2}$ Departamento de Geociências, Universidade Federal da Paraíba \\ E-mail: richardemarques@yahoo.com.br
}

\section{RESUMO}

Este estudo apresenta a aplicação do modelo hidrológico distribuído baseado em Sistema de Informações Geográficas - AÇUMOD na estimativa das vazões e potencialidades hídricas das sub-bacias do rio Pirapama, para uso do Comitê da Bacia Hidrográfica do rio Pirapama (COBH-Pirapama). A aplicação do modelo abrangeu diversas etapas, tais como: seleção dos dados de precipitação, discretização da bacia em uma malha de células e calibração empírica dos parâmetros do modelo. O modelo foi calibrado e validado com dados mensais de pluviometria para o período de 1987 a 2001. Foi constatado que os parâmetros função de infiltração, capacidade mínima de água no solo para gerar escoamento e capacidade média de armazenamento de água no solo foram os mais importantes durante o processo de calibração, influenciando diretamente no volume escoado calculado. A diferença entre o volume observado e o calculado durante os processos de calibração e validação foram respectivamente $-12,65 \%$ e $18,87 \%$. Os resultados das vazões simuladas com o modelo AÇUMOD, comparadas com as observadas mostraram que o modelo representa satisfatoriamente o comportamento hídrico da bacia e, dessa forma, pode-se considerá-lo como uma ferramenta promissora nas simulações chuva-vazão, na estimativa de curvas de permanência e na regionalização ou previsão de vazões para a bacia do rio Pirapama, bem como outras do litoral do nordeste do Brasil.

Palavras-chave: modelagem hidrológica; AÇUMOD; SIG; gestão; Pernambuco.

\section{Application of the hydrologic model AÇUMOD based on GIS for water resources management of Pirapama River, Pernambuco, Brazil}

\begin{abstract}
This study presents the application of the distributed hydrological model based on GIS AÇUMOD to estimate the water discharges and potentialities of Pirapama river sub-basins, to be used by the Pirapama River Basin Committee (COBH-Pirapama). The model application included several steps, such as: precipitation data selection, basin discretization into cells, and model parameter calibration using try-and-error technique. The model was calibrated and validated with monthly precipitation data for the period 1987-2001. It was noted that the following parameters were the most important ones during the calibration process: infiltration function, soil minimum water capacity to generate runoff, and soil mean water storage capacity, which directly affect the computed runoff volume. The difference between observed and computed runoff during the calibration and validation processes were respectively $-12.65 \%$ and $18.87 \%$. The results of the simulated discharges by AÇUMOD,
\end{abstract}


compared to observed ones, showed that the model satisfactorily represents the water basin behavior and, therefore, it can be considered a promising tool for rain-runoff simulation, permanence curve estimation, and discharge regionalization or prediction for Pirapama river basin as well as to other basins in the costal area of northeastern Brazil.

Keywords: hydrologic modeling; AÇUMOD model; GIS; management; Pernambuco.

\section{INTRODUÇÃO}

A relação da água com o planeta Terra é complexa e está diretamente associada ao crescimento da população humana, ao processo de urbanização dos grandes centros urbanos ao longo dos séculos e aos usos múltiplos da água, que afetam tanto a quantidade como a qualidade da água existente (Tundisi, 2003).

Atualmente, uma das maiores preocupações dos órgãos e comitês de bacias responsáveis pelo gerenciamento dos recursos hídricos é com os grandes períodos de escassez de água e, conseqüentemente, com a quantidade de água armazenada nos reservatórios para o abastecimento urbano em geral.

Nesse sentido, a gestão dos recursos hídricos vem se tornando uma área cada vez mais relevante no contexto dos recursos hídricos, em especial no Nordeste, principalmente, naquelas regiões mais densamente povoadas, onde o problema da falta de água é ainda mais preocupante, como é o caso da Região Metropolitana do Recife - RMR, um dos maiores aglomerados urbanos do Brasil com mais de três milhões de habitantes.

Mais recentemente, em meados da década de 1990, a RMR sofreu com dois períodos de forte estiagem em 1993-94 e 1998-99. Entre 1998-1999, o racionamento d'água foi ampliado e atingiu o seu nível de alerta mais crítico, levando quase todos os bairros da RMR a conviver com um regime severo de racionamento de água, chegando alguns locais da RMR a passarem vinte e quatro horas com água e quarenta e oito horas sem água. Ao final de 1999, um regime ainda mais severo foi implantado em alguns bairros da RMR, que chegaram a ter um dia com água e nove dias sem água, devido ao baixo volume de água armazenada nas barragens da região nesse período (Nascimento, 2003).

Uma das medidas encontradas para amenizar a escassez de água na RMR foi a construção do reservatório Pirapama, localizado na bacia do mesmo nome, para atenuar a crise no setor de abastecimento de água na RMR. Devido à importância do conhecimento da regularização das vazões dos cursos d'água nos exutórios das sub-bacias que alimentam os reservatórios responsáveis pelo abastecimento da RMR, no presente estudo optou-se por utilizar a curva de permanência como principal indicativo do comportamento hidrológico das potencialidades hídricas das sub-bacias da bacia do rio Pirapama. A curva de permanência ou de regularização relaciona a vazão ou o nível do rio e sua permanência no tempo em que a vazão é maior ou igual ao valor especificado (Tomasella, 2005).

Nos últimos anos, o Sistema de Informações Geográficas - SIG vem sendo utilizado para diversos fins em modelagem hidrológica, seja na representação do modelo de elevação do terreno, na caracterização do uso e ocupação do solo da bacia, ou na aplicação direta do acoplamento entre modelos hidrológicos num SIG. Nesse sentido, o uso do SIG permite agregar, em um único pacote, a capacidade de mapear características e de associá-las a banco de dados, o que permite análises espaciais em um curto espaço de tempo (Silva; Pruski, 2005).

Assim, o acoplamento entre modelos hidrológicos e o SIG se constitui em uma ferramenta que permite a integração entre componentes espaciais, sociais, bióticos e físicos, permitindo simulações do comportamento hidrológico, a partir da manipulação das 
características físicas da bacia, para se avaliar as possíveis alterações do uso do solo de bacias hidrográficas. Como exemplo de estudos que utilizaram a integração do SIG com modelagem hidrológica, podem-se citar os estudos de Maidment (1993), King et al. (1996), Mendes (1996), Saghafian et al. (2000), Pullar e Springer (2000), Semmens et al. (2001), e Galvíncio e Sousa (2004).

Nesse contexto, este estudo busca investigar as potencialidades hídricas da bacia do rio Pirapama, pela aplicação do modelo hidrológico distribuído e baseado em Sistema de Informações Geográficas chamado AÇUMOD, para representar o comportamento da distribuição espacial e temporal das vazões e ajudar na quantificação e análise das potencialidades da bacia do rio Pirapama. A utilização desse modelo, na modelagem das vazões das sub-bacias do rio Pirapama, busca oferecer ao comitê de bacia COBH-Pirapama uma importante ferramenta para ajudá-lo no processo de tomada de decisões.

\section{MATERIAL E MÉTODOS}

\subsection{A Área de Estudo}

A bacia hidrográfica do rio Pirapama está localizada no Estado de Pernambuco, mais precisamente na parte sul-oriental a aproximadamente $8^{\circ} 2^{2}$ ' de Latitude Sul e $35^{\circ} 00^{\prime}$ de Longitude Oeste. A bacia do rio Pirapama é composta por doze sub-bacias: Riacho Arandu, Arroio Sicupema, Rio Gurjaú, Riacho Macacos, Riacho Cajabuçu, Manoel Gonçalves, Rio Pirapama (montante), Rio Gurjaú (jusante), Gurjaú-São Braz, Rio Pirapama (jusante), Riacho Utinga de Cima, e Santa Emília (Figura 1).

O rio Pirapama nasce no município de Pombos (Mesorregião do Agreste Pernambucano), a 450 metros de altitude e percorre aproximadamente $80 \mathrm{~km}$ até seu exutório. A Bacia Pirapama é formada por vários afluentes, onde se destacam, por suas dimensões, o rio Gurjaú e os riachos dos Macacos, Cajabuçu e Arandu, ambos na margem esquerda; e os riachos Santa Amélia, Utinga de Cima e Camaçari, na margem direita. Essa rede hidrográfica limita-se ao norte com as bacias dos rios Jaboatão e Tapacurá, a oeste com a bacia do rio Ipojuca, ao sul com as bacias dos rios Massangana e Ipojuca e a leste com a bacia do rio Jaboatão (Pernambuco, 2000). A bacia ocupa parte dos municípios de Jaboatão dos Guararapes, Cabo de Santo Agostinho, Ipojuca, Moreno, Escada, Vitória de Santo Antão e Pombos, sendo, os quatros primeiros inseridos na Região Metropolitana do Recife.

\subsection{Descrição do Modelo AÇUMOD}

O modelo AÇUMOD foi desenvolvido por pesquisadores da Universidade Federal da Paraíba, com o objetivo de ajudar no planejamento e no gerenciamento dos recursos hídricos de bacias hidrográficas da região nordeste do Brasil. Uma descrição mais detalhada das funções desse modelo pode ser encontrada em Silans et al. (2000), que implementaram o modelo para a bacia do rio Piancó e que discutiram as bases relativas a sua implementação.

O AÇUMOD é um modelo hidrológico distribuído contínuo que efetua o balanço hídrico na rede de drenagem da bacia hidrográfica. O modelo é do tipo determinístico distribuído linear e é uma adaptação do modelo de Simulação a Malhas Quadradas Embutidas SIMMQE, e foi utilizado pela primeira vez pelo Departamento Nacional de Águas e Energia Elétrica, para a modelagem hidrológica da bacia do Rio Parnaíba, localizada no Estado de São Paulo, no qual obteve resultados satisfatórios na modelagem chuva-vazão (BRASIL, 1983).

Algumas modificações foram introduzidas em seus algoritmos no modelo AÇUMOD para adaptá-lo à modelagem de chuva-vazão em regiões do Nordeste do Brasil como testado 
nos estudos de Silans et al. (2000), Paiva (2000), Silva Júnior et al. (2000), Silva et al. (2004) e Silva (2005).

A utilização desse modelo foi baseada no fato de ele considerar a distribuição espacial e temporal da chuva e de informações hidroclimatológicas, tal como a evapotranspiração, além

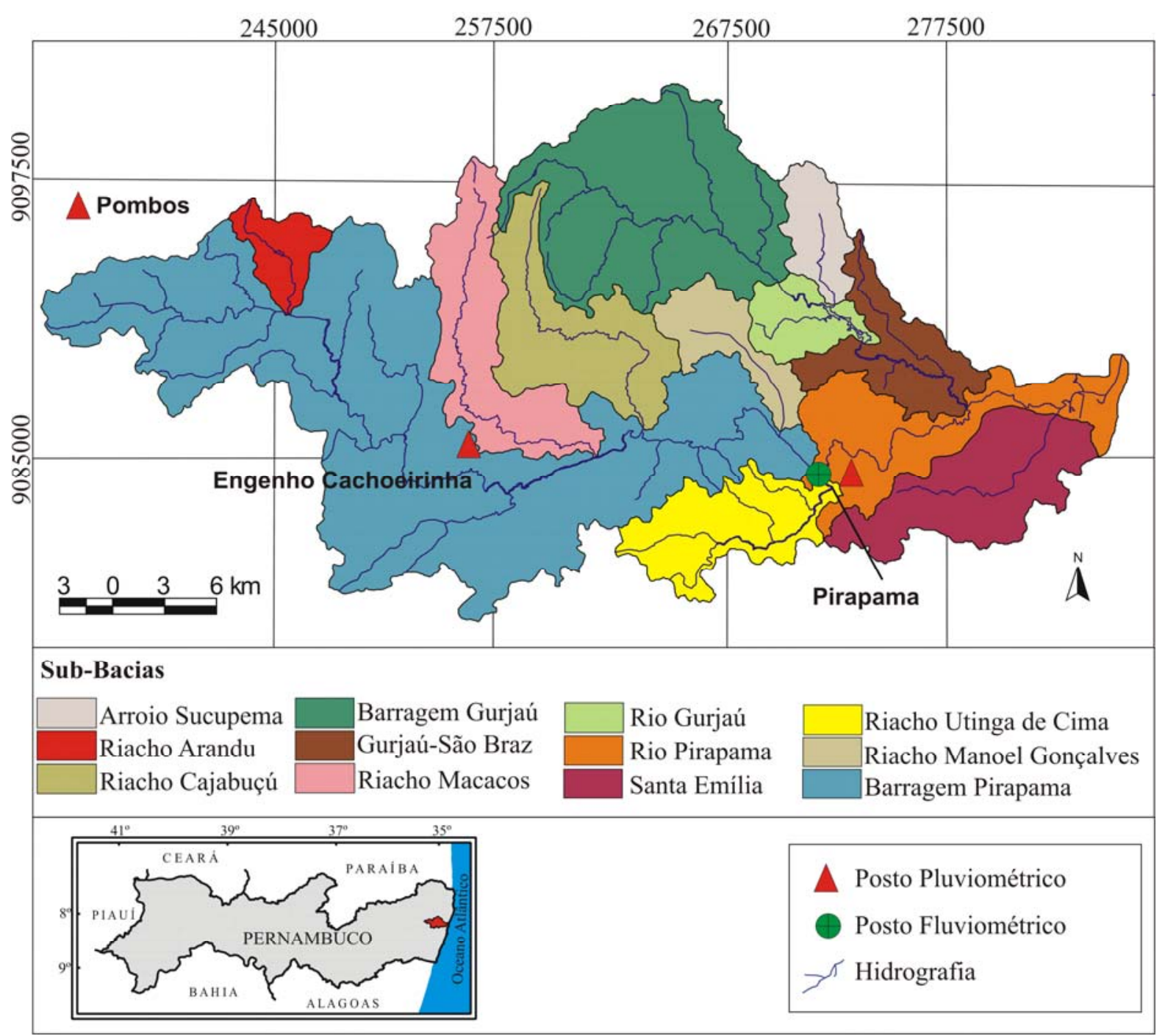

Figura 1. Localização da bacia Pirapama, sua hidrografia, sub-bacias e postos pluviométricos e fluviométrico.

de permitir as simulações das vazões em qualquer ponto previamente definido dentro da bacia. No modelo AÇUMOD, o espaço geográfico da bacia é dividido em uma malha retangular formada por células (ou quadrículas). Em cada quadrícula, o ciclo hidrológico é representado e simulado por um modelo hidrológico conceitual, por meio de um conjunto de quatro reservatórios que serão descritos na modelagem do ciclo hidrológico, os quais possuem parâmetros descritivos do ciclo para cada quadrícula (Figura 2 e Tabela 1).

\subsection{Dados utilizados}

Os dados de precipitação foram obtidos dos postos pluviométricos Pombos, Engenho Cachoeirinha e Pirapama junto à Agência Nacional de Águas e ao Laboratório de Meteorologia do Estado de Pernambuco. A localização geográfica dos postos utilizados encontra-se na Figura 1. Esse período foi escolhido por possuir a maior série de dados 
observados de precipitação para a maior quantidade de postos disponíveis na bacia e nas suas proximidades. Os dados de fluviometria foram obtidos do posto Pirapama (Figura 1), também junto à ANA para o período de 1987 a 2001, período que coincide com a chuva observada.

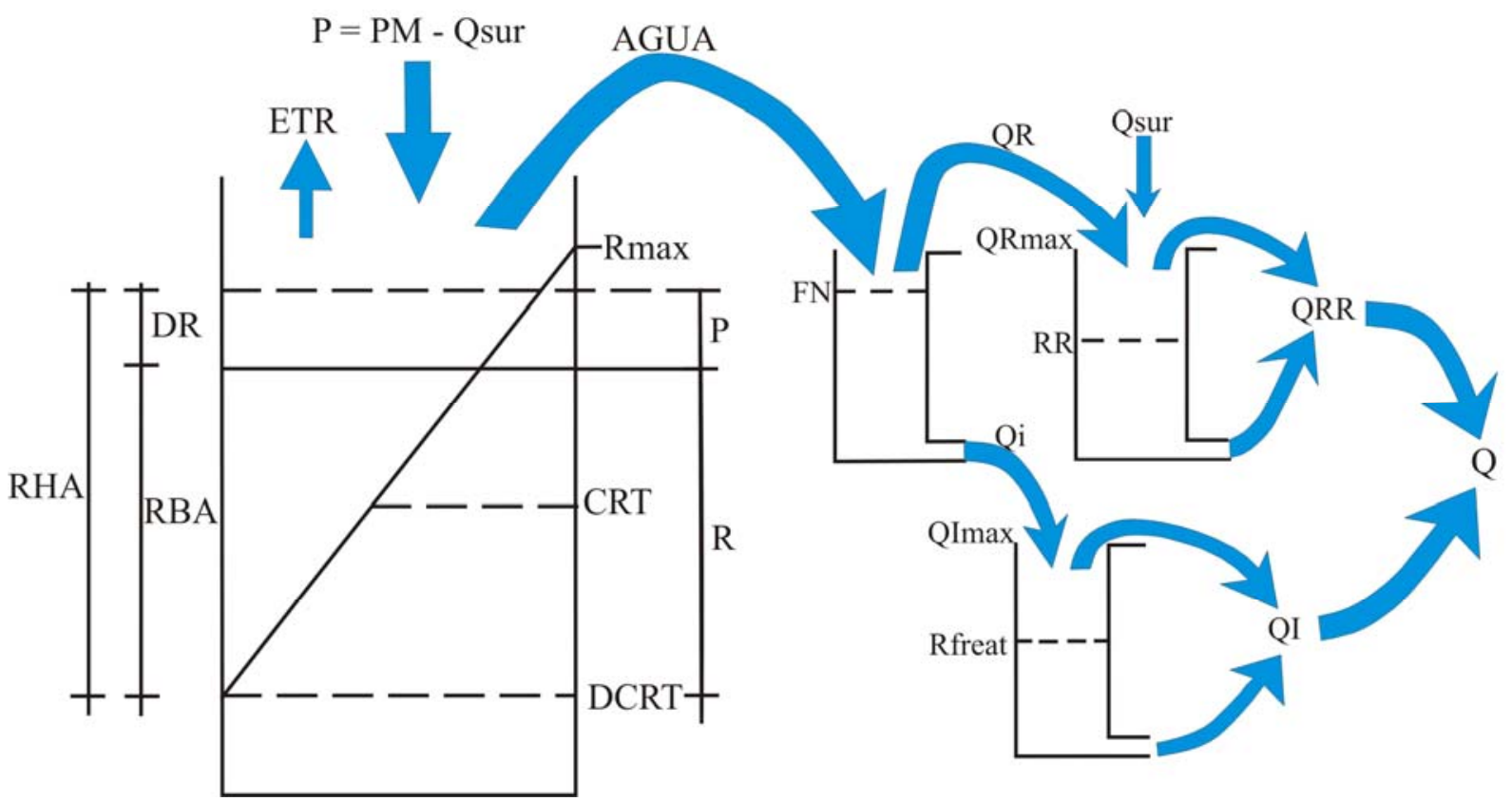

Figura 2. Conjunto dos reservatórios que simulam o ciclo hidrológico no AÇUMOD.

Tabela 1. Descrição dos parâmetros do modelo AÇUMOD.

\begin{tabular}{cl}
\hline Parâmetros & \\
\hline AGUA & quantidade de água disponível para gerar os escoamentos, em mm \\
CRT & capacidade média de armazenamento de água no solo, em mm \\
DCRT & capacidade mínima de água no solo para gerar escoamento, em mm \\
DR & variação da quantidade de água no solo, em mm \\
ETR & evapotranspiração real, em mm \\
FN & função de infiltração, em mm \\
PM & precipitação total, em mm \\
Q & lâmina escoada para uma determinada zona hidrológica homogênea \\
QI & escoamento infiltrado, antes do retardamento no reservatório subterrâneo \\
QI & nível de transbordamento do reservatório de alimentação do lençol freático \\
QR & escoamento superficial, antes do retardamento no reservatório superficial \\
QR & nível de transbordamento do reservatório de escoamento superficial \\
QRR & parcela do escoamento superficial após passar pelo reservatório solo \\
$\mathrm{Q}_{\text {sur }}$ & escoamento superficial direto \\
RBA & quantidade útil de água no solo, antes da precipitação, em mm \\
$\mathrm{R}_{\text {freat }}$ & nível de água no reservatório subterrâneo no tempo inicial, em mm \\
RHA & reserva útil de água no solo posterior à precipitação, em mm \\
$\mathrm{R}_{\max }$ & reserva máxima de água no solo, acima do qual nenhuma água é retida \\
RR & nível inicial de água no reservatório de escoamento superficial, em mm \\
\hline
\end{tabular}

Os dados observados de chuva e vazão, utilizados para a calibração e a validação do modelo, foram divididos em duas séries. A primeira de janeiro de 1987 a dezembro de 1994, período de oito anos, voltada para a calibração do modelo, e a segunda série de janeiro de 
1995 a dezembro de 2001, compreendendo um período de sete anos, a qual foi usada para a validação do modelo.

Os dados evaporimétricos utilizados no modelo foram medidos em tanque Classe $A$, e obtidos junto ao LAMEPE. Outra informação de entrada para o modelo AÇUMOD é o tempo de concentração da água na bacia. Existem muitas fórmulas para se determinar o tempo de concentração numa bacia $\left(T_{c}\right)$. No presente estudo, o $T_{c}$ foi calculado pela equação do California Highways and Public Works:

$$
T_{c}=\left(\frac{0,87 L^{3}}{H}\right)^{0,385}
$$

em que $T_{c}$ é o tempo de concentração em horas, $L$ é o comprimento do talvegue em quilômetros, sendo $H$ a diferença de cotas entre o ponto mais afastado da bacia e o ponto considerado em m, dada pela seguinte relação: $H=L I$, em que $I$ é a declividade equivalente constante em $\mathrm{m} / \mathrm{m}$. Para a bacia do rio Pirapama com $L=80,6 \mathrm{~km}$ e $H=0,403 \mathrm{~km}$, o tempo de concentração foi calculado como sendo igual a 8,91 dias.

Tabela 2. Descrição dos postos pluviométricos utilizados pelo modelo AÇUMOD.

\begin{tabular}{|c|c|c|c|c|}
\hline Código & Altitude (m) & Latitude & Longitude & Nome do Posto \\
\hline 0835137 & 290 & $8^{\circ} 09^{\prime} 00^{\prime \prime} \mathrm{S}$ & $35^{\circ} 22^{\prime} 48^{\prime \prime} \mathrm{W}$ & Pombos \\
\hline 0835068 & 360 & $8^{\circ} 13^{\prime} 30^{\prime \prime} \mathrm{S}$ & $35^{\circ} 16^{\prime} 37^{\prime \prime} \mathrm{W}$ & Engenho Cachoeirinha \\
\hline 0835138 & 30 & $8^{\circ} 16^{\prime} 43^{\prime \prime} \mathrm{S}$ & $35^{\circ} 03^{\prime} 50^{\prime \prime} \mathrm{W}$ & Pirapama \\
\hline
\end{tabular}

\subsection{Zonas Hidrologicamente Homogêneas}

As zonas hidrológicas homogêneas são definidas como regiões com a mesma produção de água para uma mesma precipitação e umidade inicial do solo. Para a discretização das zonas homogêneas, foram utilizadas técnicas de cartografia digital, como a superposição de mapas digitais da bacia de tipos de solo, de vegetação, de geologia, e de topografia. Essas zonas são utilizadas pelo AÇUMOD para a espacialização dos parâmetros em cada umas das zonas homogêneas.

As zonas hidrologicamente homogêneas para a bacia do rio Pirapama (Figura 3) foram definidas em cinco zonas homogêneas (Silva, 2005):

(a) Argilosa: esta área identificada na bacia é constituída por solos que apresentam baixas taxas de infiltração e são encontrados na parte alta da bacia.

(b) Saturada: esta zona hidrológica apresenta solos denominados de indiscriminados, constituídos principalmente por areia quartzosa, freqüentemente encontrada em praias e mangues.

(c) Latossolo: esta zona é constituída essencialmente por solos não-hidromórficos, com horizonte $A$ moderado e horizonte $B$ latossólico, de textura argilosa ou média, rico em sesquióxidos, muito porosos, além de bastante permeáveis e de acentuada a fortemente drenados, esta zona é caracterizada por solos espessos, com fraca distinção entre os horizontes, pouco fértil e com evolução antiga.

(d) Aluvial: o solo desenvolvido sobre sedimentos aluviais associados às planícies das principais drenagens da região, apresenta granulometria arenosa e horizonte $A$ bem desenvolvido. Essa zona está localizada após o reservatório Pirapama.

(e) Arenosa: esta zona ocorre na maior parte da bacia, principalmente, na sub-bacia do posto pluviométrico Pirapama e é caracterizada por uma alta taxa de infiltração. 


\subsection{Zonas pluviométricas e evaporimétricas}

As zonas pluviométricas e evaporimétricas foram calculadas para cada quadrícula discretizada da bacia, pelo método de Thiessen, que associa para cada quadrícula o posto pluviométrico mais próximo (Figura 4).

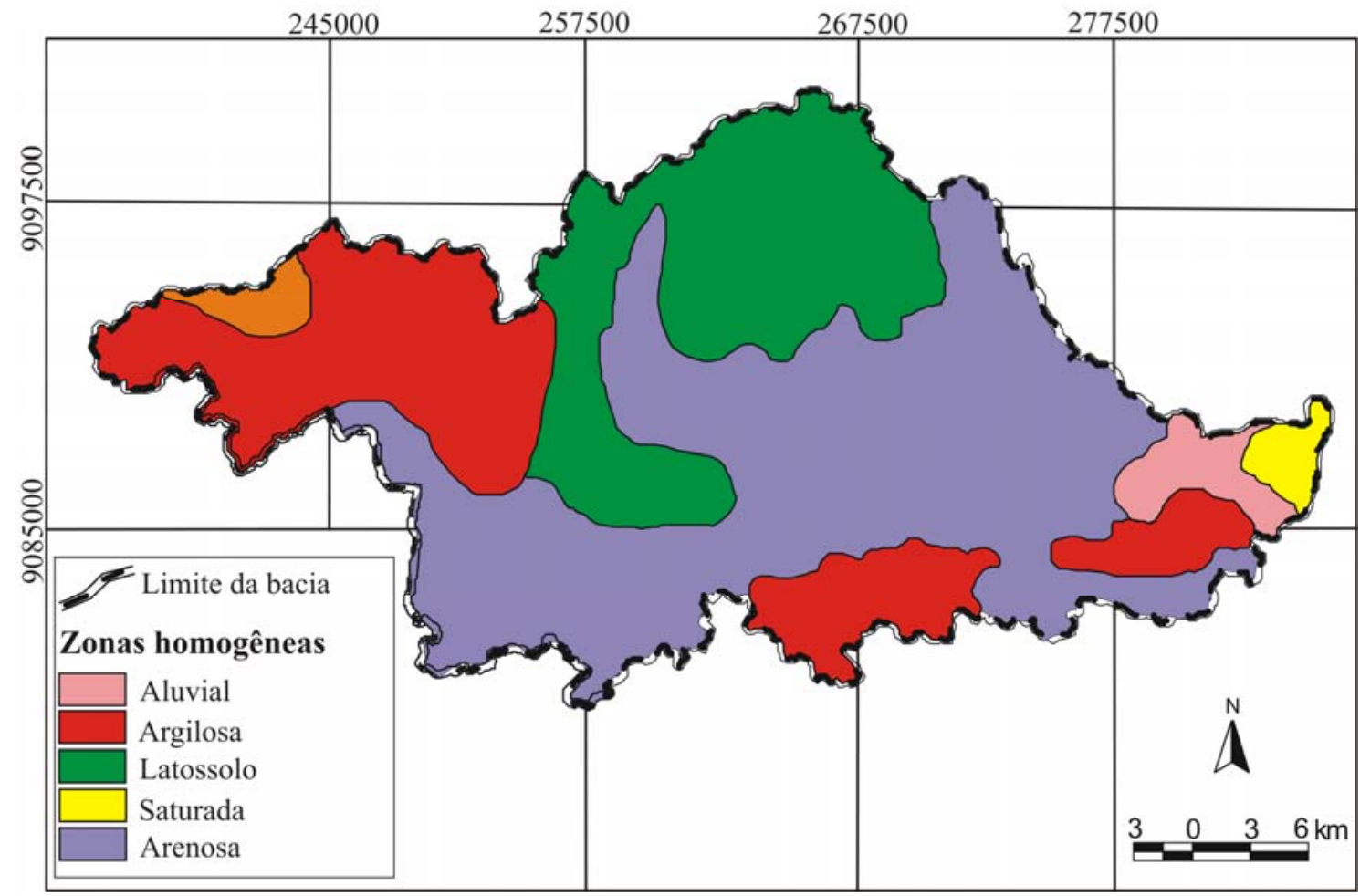

Figura 3. Mapa das zonas hidrologicamente homogêneas da bacia do rio Pirapama no modelo AÇUMOD (Silva, 2005).

A evaporação na bacia é calculada a partir das médias mensais observadas pela seleção de uma das três opções disponíveis no modelo: (a) Tanque Classe A; (b) Fórmula de Penman; e pelo (c) Método de Hargreaves. Neste trabalho foi escolhida a opção Tanque Classe A, devido à existência de uma longa série de dados observados na bacia.

Foram utilizados dados diários de precipitação observados de janeiro de 1987 a dezembro de 1994 de três postos pluviométricos (Tabela 2), e as médias mensais de evapotranspiração.

\subsection{Construção das curvas de permanência}

A curva de permanência indica a porcentagem do tempo em que qualquer descarga foi igualada ou excedida. Para a construção das curvas de permanência no presente estudo, procurou-se estabelecer intervalos de classe de vazões de acordo com a magnitude desses eventos e, no caso presente, usou-se uma metodologia proposta por Tucci (2001) para estabelecer os intervalos de classe de vazão e as respectivas freqüências acumuladas.

Após o cálculo das vazões diárias, partiu-se para a modelagem das potencialidades de cada sub-bacia pelo uso de um módulo do modelo AÇUMOD, denominado "Gerar Potencialidades das Sub-Bacias”. Esse módulo calcula algumas métricas descritivas que permitem a avaliação do modelo no período compreendido da modelagem, como: (a) desvio padrão; (b) coeficiente de assimetria; (c) coeficiente de variação; e (d) curva de permanência das vazões. No presente trabalho, são apresentadas as curvas de permanência das vazões de cada sub-bacia estudada. 
Para a construção das curvas de permanência foram utilizados dados diários da média da precipitação calculada pelo método de Thiessen dos três postos pluviométricos na bacia Pirapama. Dessa série, foram geradas vazões diárias para cada uma das doze sub-bacias.

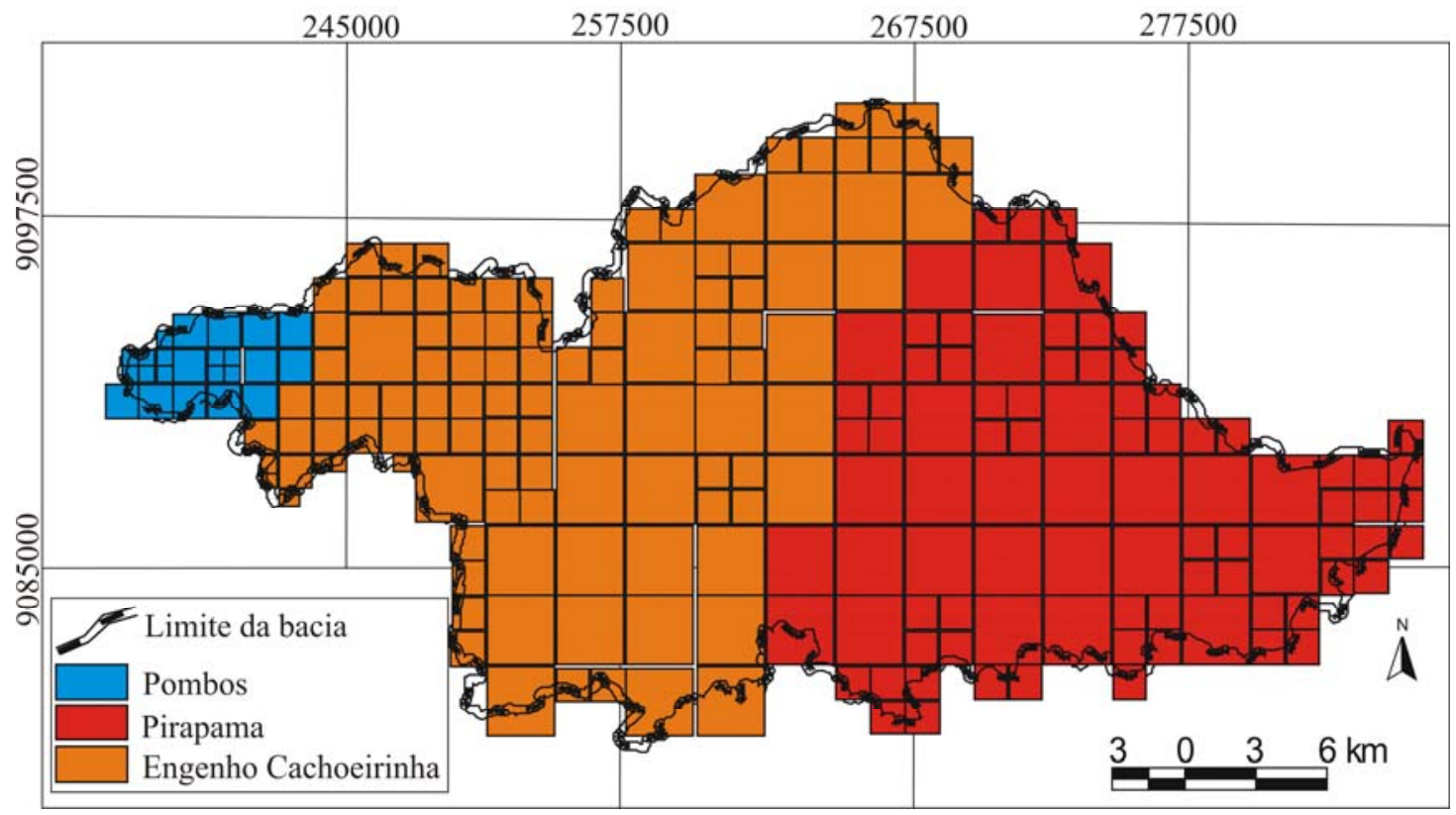

Figura 4. Representação das áreas de influência de cada posto pluviométrico da bacia do rio Pirapama no modelo AÇUMOD, calculada pelo método de Thiessen (Silva, 2005).

\section{RESULTADOS E DISCUSSÃO}

\subsection{Calibração do modelo}

Para a calibração do modelo, foram definidos a priori os valores dos parâmetros do modelo a partir da extrapolação dos valores calibrados e validados, obtidos pelos estudos de Paiva (2000) e Silva Júnior et al. (2000) para a bacia do rio Gramame, localizada próxima à bacia Pirapama e também inserida na costa oriental do Nordeste do Brasil. A calibração dos parâmetros para a bacia do rio Pirapama foi realizada empiricamente, baseando-se em diversos trabalhos e comparando-se a média mensal da vazão calculada com a média mensal da vazão observada no posto fluviométrico Pirapama.

Os valores dos parâmetros calibrados para as cinco zonas hidrológicas homogêneas (Tabela 3) mais sensíveis durante a parametrização do modelo são aqueles que definem a quantidade do escoamento: (a) CRT, que corresponde à capacidade média de armazenamento de água no solo, em milímetros; (b) DCRT, que representa a capacidade de armazenamento de água no solo, abaixo da qual não há escoamento, também medido em milímetros; (c) CQI, coeficiente que simula a descarga dos reservatórios intermediários, muito sensível nas zonas onde o escoamento de base é elevado; e (d) $F N$, parâmetro da função de infiltração, quando positivo, permite apenas que a água infiltre e, quando negativo, torna possível a infiltração e o escoamento da água; isto é, para solos profundos, esse parâmetro deve receber valores inferiores a zero, assim, quanto mais espesso for o solo, menor deverá ser o valor atribuído à zona correspondente. O parâmetro $F N$ foi ajustado com esses valores, pois a bacia do rio Pirapama está localizada sobre uma formação geológica do tipo sedimentar, a qual se caracteriza por possuir solos argilosos e profundos.

A capacidade média de armazenamento de água no solo e a infiltração tiveram uma grande influência no total do volume calculado, principalmente nas zonas argilosa, aluvial e arenosa. Essa variabilidade deve-se ao fato de que há uma enorme heterogeneidade dos solos 
na bacia, sobretudo com diferentes características de taxas de infiltração e de armazenamento d'água.

Tabela 3. Parâmetros calibrados do modelo AÇUMOD.

\begin{tabular}{ccccccccc}
\hline Parâmetros & $\boldsymbol{C R T}$ & $\boldsymbol{D C R} \boldsymbol{C}$ & $\boldsymbol{C M R}$ & $\boldsymbol{F N}$ & $\boldsymbol{Q R m a x}$ & $\boldsymbol{C Q R}$ & $\boldsymbol{Q I m a x}$ & $\boldsymbol{C Q I}$ \\
\hline Argiloso & 51 & 28 & 4,5 & -450 & 700 & 0,004 & 800 & 300 \\
Latossolo & 155 & 25 & 4,5 & -90 & 600 & 0,010 & 50 & 20 \\
Saturado & 90 & 30 & 4,5 & -60 & 650 & 0,008 & 400 & 70 \\
Aluvial & 62 & 30 & 4,5 & -85 & 850 & 0,007 & 250 & 30 \\
Arenoso & 130 & 70 & 4,5 & -70 & 450 & 0,030 & 80 & 10 \\
\hline
\end{tabular}

O hidrograma obtido durante o processo de calibração mostra que os resultados da aplicação podem ser considerados satisfatórios (Figura 5), uma vez que, foi obtido um coeficiente de correlação $\left(R^{2}\right)$ igual a 0,83 , e uma diferença entre o volume total escoado observado no período e o calculado igual a $-16,50 \%$, no período, como apresentado na Tabela 4. Com o objetivo de comparar a confiabilidade da calibração dos parâmetros do modelo, calculou-se o desvio quadrático médio (RMSE) pela equação (2), e o erro médio quadrático (MSE) pela equação (3), das vazões mensais observadas e calculadas. Os valores obtidos do RMSE e do MSE estão dispostos na Tabela 4.

$$
R M S E=\left[\frac{\sqrt{\frac{1}{N} \sum_{i=1}^{N}\left(Q_{o b s}-Q_{c a l c}\right)^{2}}}{Q m_{o b s}}\right] \times 100
$$

em que $N$ é o número de dados utilizados no processo de validação, $i$ refere-se a cada par de valores medidos e calculados, $Q_{o b s}$ é a vazão mensal observada, $Q_{c a l c}$ é a vazão mensal calculada, e $Q m_{\text {obs }}$ é a média da vazão observada.

$$
M S E=\frac{\sum_{i=1}^{N}\left(\sqrt{Q_{o b s}}-\sqrt{Q_{c a l c}}\right)^{2}}{\sum Q_{o b s}}
$$

sendo $Q_{o b s}$ e $Q_{\text {calc }}$ respectivamente as vazões observadas e calculadas.

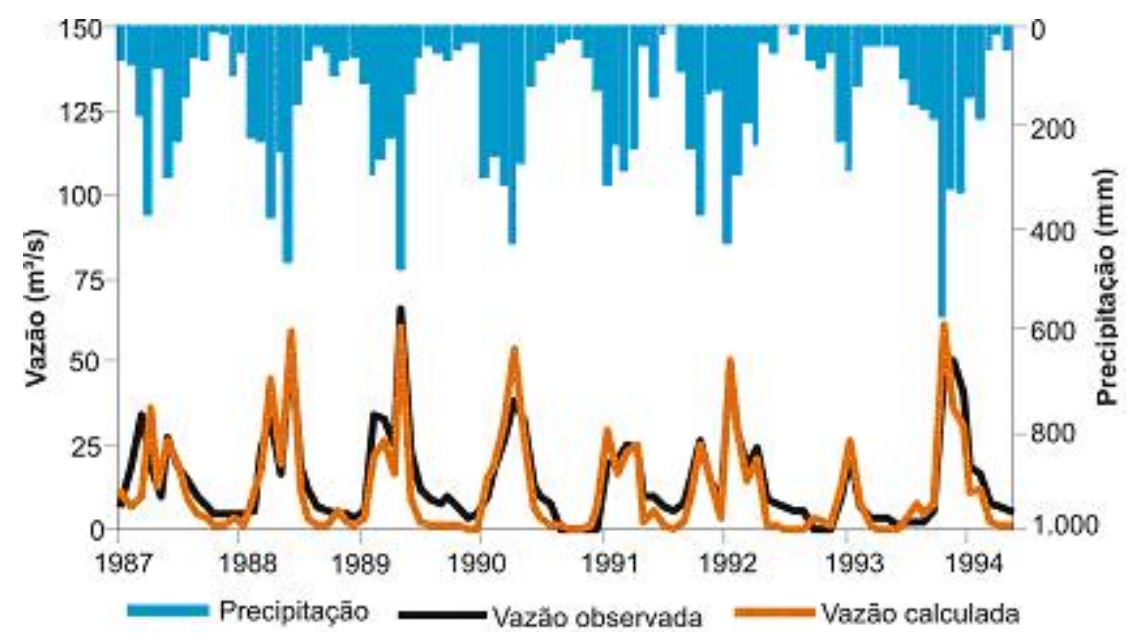

Figura 5. Hietograma médio observado e hidrogramas observados e calculados para o posto Pirapama durante a calibração do modelo. 


\subsection{Validação do modelo}

A validação de um modelo hidrológico é realizada com objetivo de verificar se os parâmetros encontrados na calibração do modelo representam satisfatoriamente as características da bacia. Dessa forma, tem-se um grau de confiabilidade para geração de vazão pelo modelo para outros períodos, principalmente no que se refere à sua utilização em estudos de monitoramento de níveis de reservatórios, seja para o controle de enchentes ou para o abastecimento d’água.

Tabela 4. Indicadores da qualidade da calibração do modelo.

\begin{tabular}{ccc}
\hline Indicadores & Calculado & Observado \\
\hline Volume $\left(\mathrm{m}^{3}\right)$ & 9.849 .254 .400 & 11.796 .019 .200 \\
Média $\left(\mathrm{m}^{3} / \mathrm{s}\right)$ & 3.115 & 3.730 \\
Correlação $\left(R^{2}\right)$ & & 0,83 \\
RMSE & \multicolumn{3}{c}{$6,90 \%$} \\
MSE & \multicolumn{3}{c}{0,087} \\
\hline
\end{tabular}

Para a validação do modelo, foram utilizados dados diários de precipitação observados de janeiro de 1995 a dezembro de 2002 dos mesmos postos pluviométricos. Os resultados da comparação entre as vazões calculadas e as observadas mostraram um excelente coeficiente de correlação $\left(R^{2}\right)$, e valores considerados satisfatórios para o RMSE e o MSE (Tabela 5).

Os dados de vazão referentes ao ano de 2002 para o posto Pirapama não foram utilizados na validação do modelo devido a pouca confiabilidade dos valores observados, pois com a construção da Barragem Pirapama, localizada a montante do posto Pirapama, a série de vazão para esse posto não representaria mais a vazão natural do rio.

A Figura 6 apresenta a precipitação média da bacia calculada pelo método de Thiessen e são expostas as vazões calculadas pelo modelo, na fase de validação, e as vazões observadas no período de 1995 a 2001.

Tabela 5. Indicadores da qualidade da validação do modelo.

\begin{tabular}{ccc}
\hline & Calculado & Observado \\
\hline Volume $\left(\mathrm{m}^{3}\right)$ & 10.235 .116 .800 & 8.610 .624 .000 \\
Média $\left(\mathrm{m}^{3} / \mathrm{s}\right)$ & 3.237 & 2.723 \\
Correlação $\left(R^{2}\right)$ & \multicolumn{3}{c}{0,89} \\
RMSE & \multicolumn{3}{c}{$28,16 \%$} \\
MSE & \multicolumn{3}{c}{0,083} \\
\hline
\end{tabular}

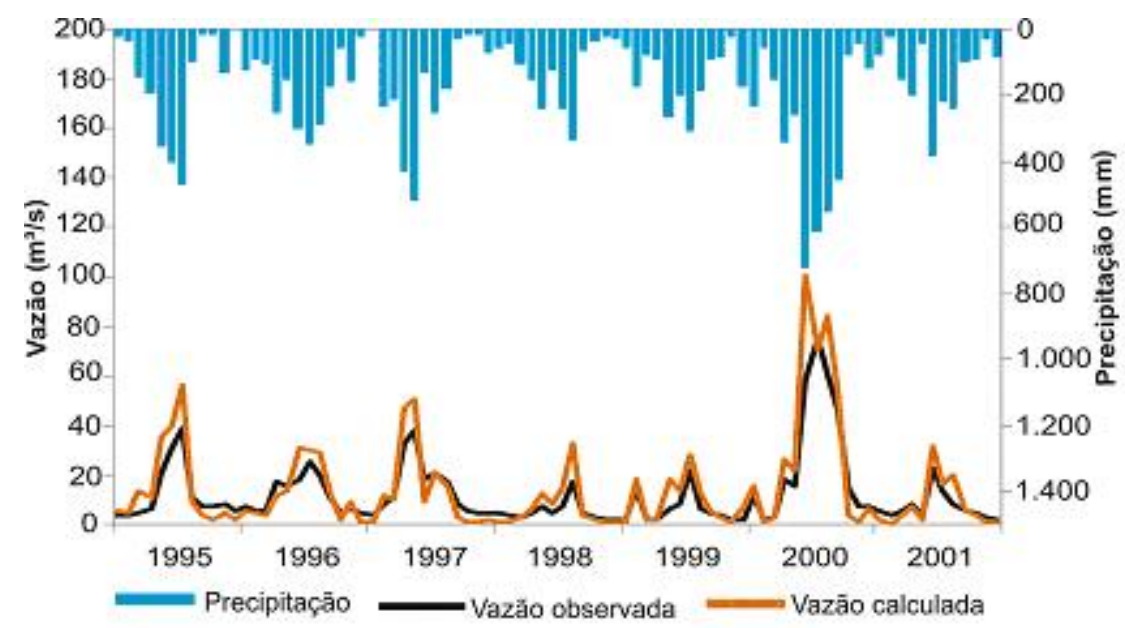

Figura 6. Hietograma médio observado e hidrogramas observados e calculados para o posto Pirapama durante a validação do modelo. 


\subsection{Potencialidades das Sub-Bacias do Rio Pirapama}

As vazões máximas calculadas para as sub-bacias do rio Pirapama foram obtidas pela equação [4]. Para o cálculo das potencialidades das sub-bacias foram escolhidas duas porcentagens que poderiam ser outorgadas (20 e 30\%), uma vez que não existe um valor definido para o Estado de Pernambuco. Os resultados das vazões máximas calculadas são apresentados na Tabela 6.

$$
Q_{\max }=X Q_{n \%}(t)
$$

em que $Q_{\max }$ é o volume máximo a ser outorgado pelo requisitante, $X$ é o percentual permitido pela legislação, e $\mathrm{Q}_{n \%}(t)$ é a vazão que é superada em $n \%$ no tempo; e.g., $Q_{50}$ é a vazão que é superada em $50 \%$ do tempo, conhecida também como mediana das vazões, e $Q_{90}$ é aquela em que a vazão é superada em $90 \%$ do tempo.

A Figura 7 apresenta as curvas de permanência simuladas para cada sub-bacia da bacia Pirapama. Os resultados obtidos mostraram que as sub-bacias com maior potencialidade hídrica são Rio Pirapama, com vazões $Q_{50}$ igual a 17,8m³/s e $Q_{90}$ igual a 10,0m³/s (Figura 7j), e Gurjaú-São Braz, com vazões $Q_{50}$ igual a $15,6 \mathrm{~m}^{3} / \mathrm{s}$ e $Q_{90}$ igual a $8,1 \mathrm{~m}^{3} / \mathrm{s}$ (Figura $7 \mathrm{i}$ ).

Com relação às menores potencialidades hídricas, as sub-bacias de Manoel Gonçalves (Figura 7f), Cajabuçu (Figura 7e), Utinga de Cima (Figura 7l) e Arandu (Figura 7a) foram as que apresentaram as menores vazões nos seus exutórios, todas com $Q_{50}$ abaixo de $1,0 \mathrm{~m}^{3} / \mathrm{s}$ e $Q_{90}$ inferior a $0,5 \mathrm{~m}^{3} / \mathrm{s}$.

Tabela 6. Vazões calculadas para as sub-bacias do rio Pirapama.

\begin{tabular}{|c|c|c|c|c|c|c|}
\hline \multirow{2}{*}{ SUB-BACIA } & \multirow{2}{*}{$\begin{array}{c}Q_{50} \\
\left(\mathrm{~m}^{3} / \mathrm{s}\right)\end{array}$} & \multirow{2}{*}{$\begin{array}{c}Q_{90} \\
\left(\mathrm{~m}^{3} / \mathrm{s}\right)\end{array}$} & \multicolumn{4}{|c|}{$Q_{\max }\left(\mathrm{m}^{3} / \mathrm{s}\right)$} \\
\hline & & & $20 \% Q_{50}$ & $30 \% Q_{50}$ & $20 \% Q_{90}$ & $30 \% Q_{90}$ \\
\hline Arandu & 1,0 & 0,3 & 0,2 & 0,3 & 0,1 & 0,1 \\
\hline Barragem Gurjaú & 3,1 & 1,6 & 0,6 & 0,9 & 0,3 & 0,5 \\
\hline Barragem Pirapama & 10,5 & 4,0 & 2,1 & 3,2 & 0,8 & 1,2 \\
\hline Cajabuçu & 0,9 & 0,3 & 0,2 & 0,3 & 0,1 & 0,1 \\
\hline Gurjaú-São Braz & 15,6 & 8,1 & 3,1 & 4,7 & 1,6 & 2,4 \\
\hline Macacos & 8,4 & 4,5 & 1,7 & 2,5 & 0,9 & 1,4 \\
\hline Manoel Gonçalves & 0,4 & 0,2 & 0,1 & 0,1 & 0,0 & 0,1 \\
\hline Rio Gurjaú & 0,2 & 0,1 & 0,1 & 0,1 & 0,0 & 0,0 \\
\hline Rio Pirapama & 17,8 & 10,0 & 3,6 & 5,3 & 2,0 & 3,0 \\
\hline Santa Emília & 1,2 & 0,3 & 0,2 & 0,4 & 0,1 & 0,1 \\
\hline Sicupema & 3,1 & 1,7 & 0,6 & 0,9 & 0,3 & 0,5 \\
\hline Utinga de Cima & 1,0 & 0,3 & 0,2 & 0,3 & 0,1 & 0,1 \\
\hline
\end{tabular}

\section{CONCLUSÕES}

O modelo hidrológico estudado se caracteriza pela capacidade de tratar grandes sistemas de recursos hídricos de forma a representar de forma eficiente as vazões observadas e calculadas, possuindo capacidade de adaptação a uma grande variedade de problemas de análises de sistemas de aproveitamentos hídricos, além de proporcionar uma fácil representação dos resultados pelas interfaces amigáveis. Esse tipo de modelo permite quando necessário alterar a estrutura e as regras operacionais dos sistemas, além de tolerar a alteração no formato dos dados de entrada, possibilitando a análise de vários cenários indispensáveis para o planejamento e manejo de recursos hídricos.

As zonas homogêneas, zonas argilosa, aluvial e arenosa apresentaram os maiores volumes escoados. Essa variabilidade deve-se ao fato de que há uma enorme heterogeneidade dos solos na bacia, sobretudo com diferentes características de taxas de infiltração e de 
armazenamento d’água. O modelo apresenta em seu algoritmo uma característica que permite caracterizar a distribuição espacial dos postos fluviométricos, além de determinar as potencialidades de cada sub-bacia.

Conclui-se do que foi exposto que dentre todas as sub-bacias constituintes da bacia hidrográfica do rio Pirapama, aquela com menor potencialidade hídrica foi a sub-bacia do Rio Gurjaú (jusante) com vazões médias em torno de $0,2 \mathrm{~m} 3 / \mathrm{s}$. Já a sub-bacia com maior potencial

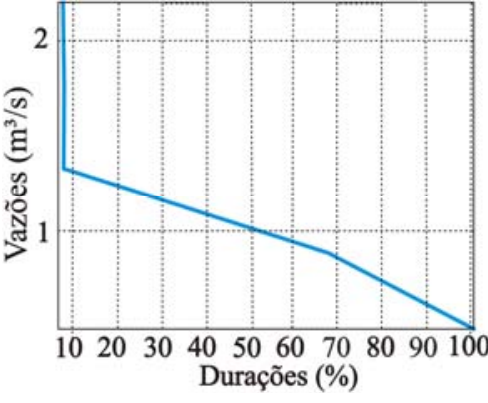

a) Riacho Arandu

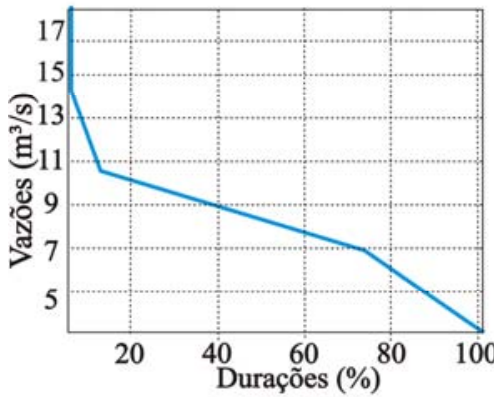

d) Riacho Macacos

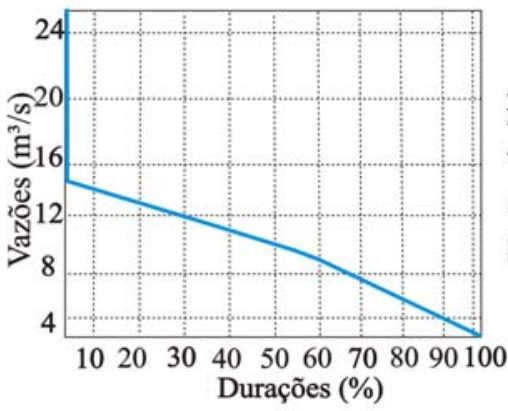

g) Barragem Pirapama

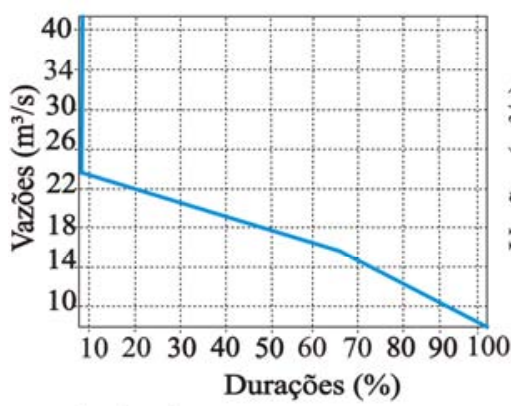

j) Rio Pirapama

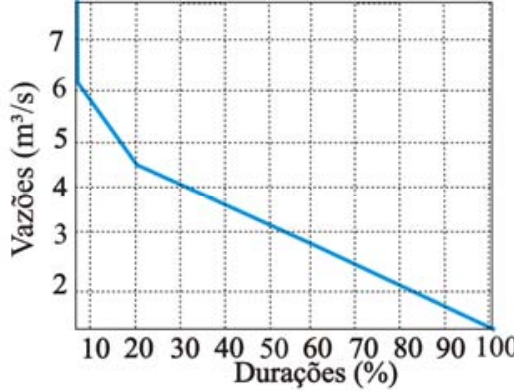

b)Arroio Sicupema

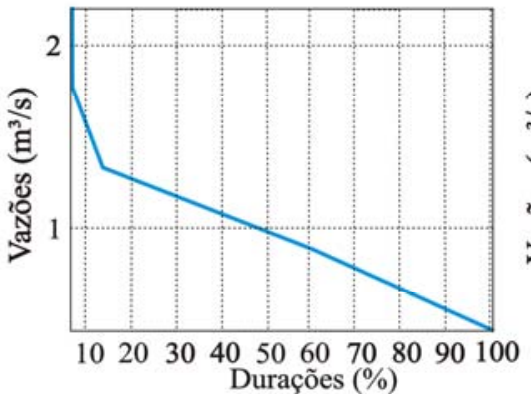

e) Riacho Cajabuçu

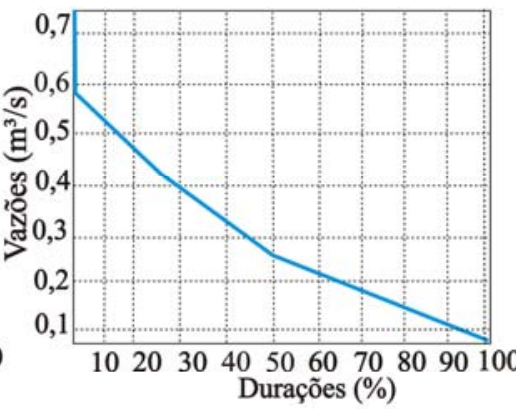

h) Rio Gurjaú

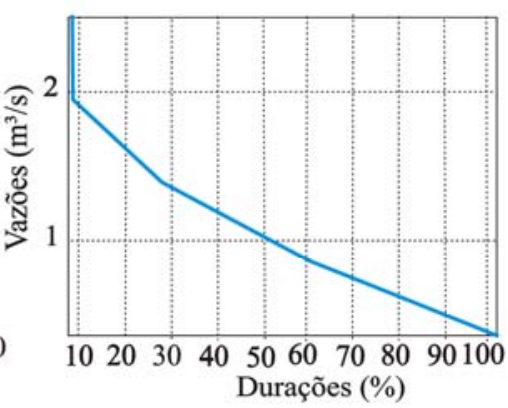

1) Riacho Utinga de Cima

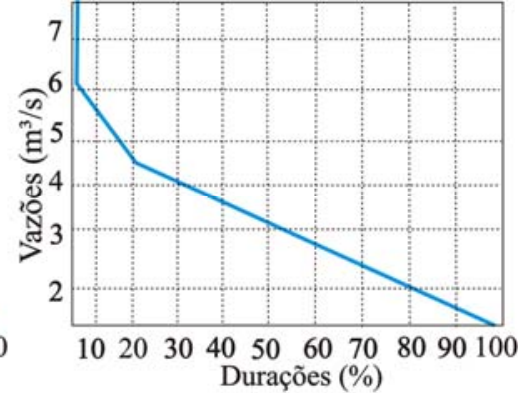

c) Barragem Gurjaú

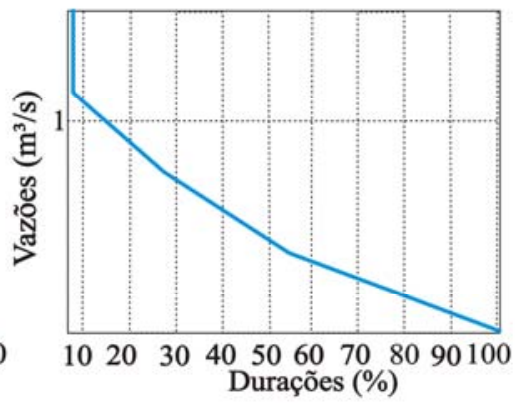

f) Riacho Manoel Gonçalves

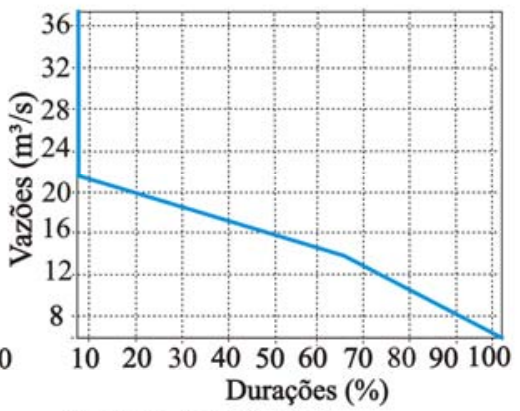

i) Rio Gurjaú-São Braz

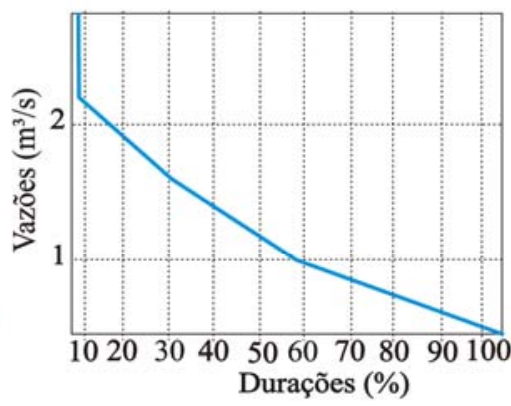

m) Riacho Santa Emília

Figura 7. Curva de permanência de vazão das sub-bacias do Rio Pirapama, entre 1987 e 2001. 
hídrico foi a sub-bacia do Rio Pirapama (jusante) com vazões médias variando de 40 a 20 $\mathrm{m}^{3} / \mathrm{s}$ com uma curva de permanência de $60 \%$ no período avaliado.

Os resultados obtidos são promissores, podendo o modelo ser considerado como uma ferramenta promissora na simulação de vazões em qualquer ponto da bacia, o que atende aos propósitos do comitê da bacia.

\section{AGRADECIMENTOS}

Os autores agradecem ao Prof. Dr. Alain Marie Passerat de Silans, do Laboratório de Recursos Hídricos e Engenharia Ambiental da UFPB, por fornecer o programa fonte utilizado no estudo, e à ANA (Agência Nacional de Águas) pela disponibilização dos dados utilizados. Os autores também foram apoiados com recursos e bolsas do CNPq e do MCT/CT-Hidro.

\section{REFERÊNCIAS}

BRASIL. Ministério de Minas e Energia. Departamento Nacional de Águas e Energia Elétrica. Modelo SIMMQE: conceituação. Brasília, 1983. 50 p.

GALVÍNCIO, J. D.; SOUSA F. A. S. Uso do modelo TOPAZ para a caracterização fisiográfica da bacia hidrográfica do Açude Epitácio Pessoa. Revista Brasileira de Recursos Hídricos, Porto Alegre, v. 9, n. 4, p. 120-139, 2004.

KING, K. W.; ARNOLD, J. G.; WILLIAMS, J. R.; SRINIVASAN, R. Soil and water assessment tool: SWAT. Temple: USDA, 1996. 450 p.

MAIDMENT, D. R. Developing a spatially distributed unit hydrograph by using GIS. In: DOVAR, K.; NATCHNEBEL, H. P. Application of geographic information systems in hydrology and water resources. In: VIENNA CONFERENCE, 1993, Viena. Proceedings... Viena: Int. Assoc. of Hydrological Sci., 1993. p. 181-192.

MENDES, C. A. B. Integração de modelos hidrológicos e sistemas de informações geográficas: fundamentos. Revista Brasileira de Recursos Hídricos, Porto Alegre, v. 1, n. 1, p. 47-66, 1996.

NASCIMENTO, B. B. Vulnerabilidade do sistema de abastecimento de água potável da Região Metropolitana do Recife: intermitência e poluição. 2003. 250f. Dissertação (Mestrado em Gestão e Políticas Ambientais) - Universidade de Pernambuco, Recife, 2003.

PAIVA, A. E. D. B. Simulações hidrológicas na bacia do rio Gramame como subsídio ao processo de outorga. 2000. 156f. Dissertação (Mestrado em Engenharia Civil) Universidade Federal da Paraíba, Campina Grande, 2000.

PERNAMBUCO. Agência Estadual de Meio Ambiente e Recursos Hídricos. Companhia Pernambucana do Meio Ambiente. Agenda 21: Bacia do Pirapama: zoneamento ecológico-econômico. Recife: CPRH/DFID, 2000. 250 p.

PULLAR, D.; SPRINGER, D. Towards integrating GIS and catchment models. Journal of Hydrology, Amsterdam, v. 15, n. 5, p. 451-459, 2000. 
SAGHAFIAN, B.; VAN LIESHOUT A. M.; RAJAEIL, H. M. Distributed catchment simulation using a raster GIS. Environmental Modeling and Software, Canberra, v. 2, n. 3/4, p. 199-203, 2000.

SEMMENS, D. J.; MILLER, S. N.; HERNANDEZ, M.; BURNS, I. S.; MILLER, W. P.; GOODRICH, D. C. Automated geospatial watershed assessment (AGWA) - a GISbased hydrologic modeling tool: documentation and user manual. Tucson: USDAARS, 2001.

SILANS, A. M. B. P.; PAIVA, A. E. D. B.; ALMEIDA, C. N.; ALBUQUERQUE, D. J. S. Aplicação do modelo hidrológico distribuído AÇUMOD à bacia hidrográfica do rio do Peixe - Estado da Paraíba. Revista Brasileira de Recursos Hídricos, Porto Alegre, v. 5, n. 3, p. 26-39, 2000.

SILVA JÚNIOR, A. N.; SILANS, A. M. B. P.; PAIVA, A. E. D. B.; ALMEIDA, C. N. Aplicação do modelo hidrológico distribuído AÇUMOD à bacia hidrográfica do rio Gramame - Estado da Paraíba. In: SILVA, T. C.; GADELHA, C. L. M.; SILANS, A. M. B. P. (org.). Bacia do rio Gramame: hidrologia e aspectos ambientais para gestão dos seus recursos hídricos. João Pessoa: Editora Universitária/UFPB, 2000. p. 48-56.

SILVA, D. D.; PRUSKI, F. F. Gestão de recursos hídricos: aspectos legais, econômicos, administrativos e sociais. Viçosa: Universidade Federal de Viçosa, 2005.

SILVA, R. M. Previsão hidrossedimentológica numa bacia periurbana através do acoplamento de modelos de previsão climática e hidrológica. 2005. 171f. Dissertação (Mestrado em Engenharia Urbana) - Universidade Federal da Paraíba, João Pessoa, 2005.

SILVA, R. M.; SANTOS, C. A. G.; MARINHO, L. S.; NITÃO, I. A. Application of a distributed hydrologic and geographically referenced model to Pirapama river basin. In: IBERIAN LATIN AMERICAN CONGRESS ON COMPUTATIONAL METHODS, 25., 2004, Recife. Proceedings... Recife: CILAMCE, 2004. 1 CD-ROM.

TOMASELLA, J. Permanência de cotas/vazões entre 1986 e 1996 em algumas bacias brasileiras. Climanálise, São José dos Campos, v. 20, n. 7, p. 15-29, 2005.

TUCCI, C. E. Hidrologia: ciência e aplicação. 2. ed. Porto Alegre: Editora da Universidade Federal do Rio Grande do Sul, 2001. 943p.

TUNDISI, J. G. Água no século XXI: enfrentando a escassez. São Carlos: Rima, 2003. 156 p. 